\title{
Chylothorax in a Patient with Pulmonary Aspergillosis and Chronic Renal Disease in Hemodialysis
}

\author{
Jorge I Miranda ${ }^{1,2^{*}}$, Lenín O Guevara Gutiérrez ${ }^{3}$, Aracely A Siu Blanco ${ }^{4}$, Carlos J Quant Durán ${ }^{2,5}$, Sumaya E Moreira López² and Alfredo \\ Celedón Lacayo 6
}

${ }^{1}$ Department of Pulmonology, Hospital Monte España, Semáforos Villa Fontana 150 vrs Norte Managua, Managua, Nicaragua

${ }^{2}$ Department of Internal Medicine, Hospital Metropolitano Vivian Pellas, Managua, Nicaragua

${ }^{3}$ Department of Interventional-Radiology, Military Hospital School Alejandro Dávila Bolaños, Managua, Nicaragua

${ }^{4}$ Department of Internal Medicine and Department of Nephrology, Hospital Monte España, Managua, Nicaragua

${ }^{5}$ Department of Internal Medicine and Department of Infectious Diseases, Hospital Dr. Roberto Calderón Gutiérrez, Managua, Nicaragua, Hospital Metropolitano Vivian Pellas, Managua, Nicaragua

${ }^{6}$ Department of Surgery, Metropolitan Hospital Vivian Pellas $3^{\text {rd }}$ Floor, Managua, Nicaragua

\begin{abstract}
Chylothorax is the accumulation of lymphatic fluid (chyle) in the pleural space, as a result of obstruction, injury or leakage of the thoracic duct or one of its tributaries. The frequency of causes of chylothorax depends on the type of hospital and the population served but there are few reports of this complication in people with end- stage renal disease and the outcomes with different interventions. We report the case of a 35-years-old man from a low-altitude agricultural community in northwest Nicaragua, diagnosed with end-stage chronic kidney disease (CKD) of nontraditional etiology three months before admission who developed chylothorax after dysfunction of central venous catheter (CVC) at the right internal jugular vein for hemodialysis. After multidisciplinary approach, we found no cause of the chylothorax other than pulmonary Aspergillosis with mediastinal adenopathy and possible external pressure to the thoracic duct as a mechanism similar described in pulmonary tuberculosis, sarcoidosis and histoplasmosis. Chylothorax resolved with the treatment for aspergillosis and performance of lymphangiography with lipiodol after conservative treatment for chylothorax failed and before we continued to embolization of the thoracic duct, which allowed us to performance pleurodesis with iodine without complications. We reviewed the etiologies of chylothorax in patients with end-stage renal disease in hemodialysis reported so far and found no reports of aspergillosis as a cause of chylothorax.
\end{abstract}

Keywords: Chylothorax; Chylous effusion; Cholesterol effusion; End stage renal disease; Hemodialysis; Adults; CVC complication; Pulmonary aspergillosis; Lymphangiography

\section{Introduction}

Chylothorax is a life-threatening clinical entity and is defined as the accumulation of lymphatic fluid (chyle) in the pleural space due to obstruction, injury or leakage of the thoracic duct or one of its tributaries [1].

Chyle is a milk, white opalescent, odorless liquid that forms when the long chain triglycerides in the diet are transformed into chylomicrons and low molecular weight lipoproteins secreted in the intestine and transported in the lymphatic channels which coalesce in the lymphatic cistern and form the thoracic duct (TD) at the level of the L2 vertebra, which enters the thoracic cavity through the oesophageal hiatus, ascends extrapleurally through the posterior mediastinum along the right surface of the spine, crosses the left side at the level of the main carina, leaves the mediastinum forming an arch above the clavicle and descends to drain at the junction of the left internal jugular and subclavian vein; however, only $50 \%$ of the subjects present this route, because considerable anatomic variation has been described and the thoracic duct may also drain in to the left internal jugular vein $[2,3]$.

Accumulation of lymphatic fluid in the pleural cavity can occur through three mechanisms: 1) Traumatic rupture of the duct or its tributaries, 2) Obstruction of the thoracic duct that causes increased intraluminal pressure with escape of lymph out the lymphatics and 3) Transdiaphragmatic flow from a chylous peritoneal fluid [4].

Since up to $13 \%$ of chylothorax can have a non-milky macroscopic appearance and milky pleural fluid may be due to other etiologies (pseudochylothorax, empyema) it is important to maintain a high index of suspicion and look for the diagnostic criteria: 1) Triglycerides $\geq 110 \mathrm{mg} / \mathrm{dl}$ in pleural fluid, usually on a lymphocytic exudate. 2) Presence of chylomicrons in pleural fluid (lipid electrophoresis) and 3) Lymphangiography (LAG) showing chyle leakage into the pleural cavity [4].

The frequency of the causes of chylothorax depends on the type of hospital and the population served, but are generally classified as traumatic and non-traumatic causes (Figure 1).

\section{Case Report}

A 35-years-old man from a low-altitude agricultural community in northwest Nicaragua diagnosed with end stage chronic kidney disease (CKD) of non-traditional etiology three months before admission who was admitted for a hypertensive emergency that resolved quickly in emergency department with nitroglycerine infusion, but developed dyspnea during the hospitalization.

He was stable and adherent to hemodialysis for three months via

*Corresponding author: Jorge Iván Miranda, Department of Pulmonology Hospital Monte España, Sémaforos Villa Fontana 150 vrs Norte Mnanagua Managua 14042, Nicaragua, Tel: 50585122996; E-mail: jor30mir@yahoo.com

Received January 03, 2019; Accepted January 23, 2019; Published February 01, 2019

Citation: Miranda JI, Gutiérrez LOG, Blanco AAS, Durán CJQ, López SEM, et al. (2019) Chylothorax in a Patient with Pulmonary Aspergillosis and Chronic Renal Disease in Hemodialysis. J Pulm Respir Med 9: 484. doi: 10.4172/2161105X.1000484

Copyright: (c) 2019 Miranda Jl, et al. This is an open-access article distributed under the terms of the Creative Commons Attribution License, which permits unrestricted use, distribution, and reproduction in any medium, provided the original author and source are credited. 


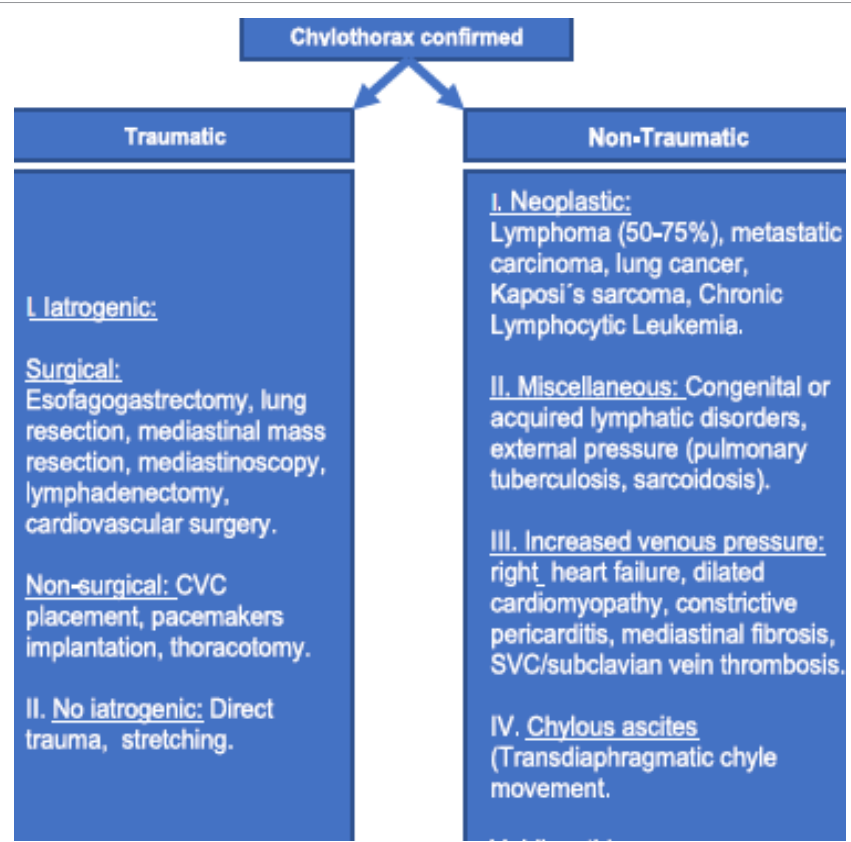

Figure 1: Etiopathogenic classification of chylothorax.

right internal jugular catheter, however by the time the patient arrived our hospital presented catheter dysfunction because a clot of two centimeters long. He recently had arteriovenous fistula created in his right upper extremity and required venous access on contralateral side for hemodialysis until the fistula matured, so the catheter was replaced with a left internal jugular vein CVC under ultrasound guide. $\mathrm{He}$ denied recent trauma, fever, chills or cough. Medications at the time of presentation were amlodipine, pantoprazole and carvedilol.

On clinical examination patient was afebrile, showed oxygen saturation of $89 \%$ on room air, respiratory rate 24 breaths per minute, blood pressure of $124 / 73 \mathrm{mmHg}$ and heart rate of 100 beats per minute. No evidence of thyroid or lymph node swelling at neck was observed, neither supraclavicular nor inguinal adenopathy.

There was reduced expansion on the right side of the chest, absence of breath sounds and dull percussion noted over medial and basal right lung fields, and crackles detected above this zone.

A chest radiography showed a large right pleural effusion (Figure 2 ), associated with multiple alveolar opacities more evident after the removal of fluid. He had a normal white cell count of 7,940 per $\mathrm{mm}^{3}$, mild anemia, controlled uremia and slightly elevated inflammation markers (Table 1).

A thoracocentesis was performed draining yellow creamy, cloudy, odorless effusion fluid (Figure 3). Intravenous meropenem was given for a presumed empyema, dyspnea and hypoxemia improved after drainage but infectious disease department sought a respiratory opinion and because the results of pleural fluid analysis (Table 2) a diagnosis of typical chylothorax was made. Gram stain and cultures showed no organism, acid-fast bacilli smear and Xpert for tuberculosis were negatives.

Pulmonary department insert a chest drain tube that produced over $500 \mathrm{~mL}$ of fluid daily in the first week despite conservative management with diet and use of subcutaneous octreotide, meanwhile completed the

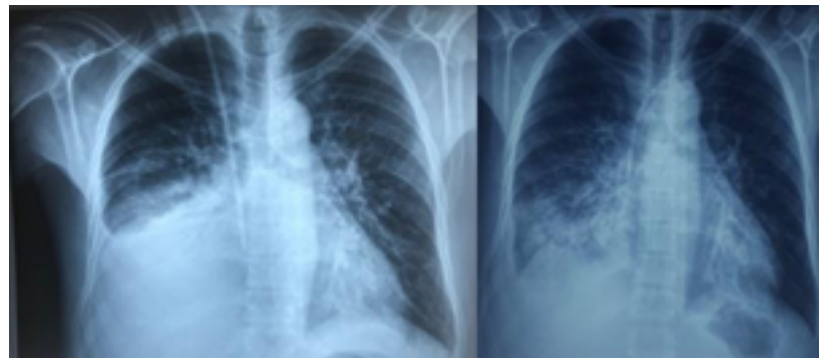

Figure 2: Chest radiography on admission. Before and after thoracocentesis and replaced catheter.

evaluation of the cause with a thoracic CT scan (Figure 4) that confirm the unilateral right-sided large pleural fluid, presence of enlarged mediastinal lymph and coalescent-nodular opacities at ipsilateral upper and middle lobes.

A bronchoscopy reveals a high tittle positive enzyme immunoassay for galactomannan antigen in bronchioloalveolar lavage (BAL) which was negative for other organism in cultures, acid-fast bacilli smear and Xpert for tuberculosis. Cytology and bronchial biopsy were negative for malignancy.

Bronchoscopy also found extrinsic compression at level of the upper lobe Inter-lobar carina, presumably caused by enlarged mediastinal lymph nodes (Figure 5).

Since pulmonary aspergillosis is not recognized as a cause of chylothorax, we searched for common causes described in this population, at the same time started anti-fungal therapy with endovenous voriconazole.

A venous phased Angio-Tomography ruled out obstruction/ thrombosis of neck and central veins (Figure 6), thus we proposed the performance of LAG for interventional-radiology department with the aim to rule out direct TD injury during previous replacement of CVC, identify the site of leakage and eventually to embolize TD.

The Intranodal lymphangiography was performed in a standard fashion: In brief, ultrasound of the inguinal and medial upper thigh was performed using a linear transducer to identify a lymph node, which was directly accessed under real-time ultrasound guidance with a 25-gauge spinal needle preassembled and attached to a short segment of intravenous tubing and a $3-\mathrm{mL}$ polycarbonate syringe containing an oil-based contrast agent (Lipiodol). Once the initial injection was observed under fluoroscopy to confirm proper positioning of the needle, contrast was injected by hand at a rate of approximately $1 \mathrm{~mL}$ per 5 minutes (median, $12 \mathrm{~mL}$; range, $8-40 \mathrm{~mL}$ ), and progression of the contrast was followed by intermittent fluoroscopy, not reporting any leakage, obstruction or mass in TD after two sessions on consecutive days (Figure 7).

Twenty-four hours after the second LAG was performed the rate of fluid production diminished to $150 \mathrm{~mL}$ per day and in the following 5 days; pleural fluid was clarifying until it was serous. At this time, patient completed two weeks of intravenous anti-fungal therapy. A decision was made to perform a pleurodesis with iodine that was successful and without complications.

Patient was discharged after completed 4 weeks of intravenous anti-fungal treatment. He did not need additional pleural aspirations 
Citation: Miranda JI, Gutiérrez LOG, Blanco AAS, Durán CJQ, López SEM, et al. (2019) Chylothorax in a Patient with Pulmonary Aspergillosis and Chronic Renal Disease in Hemodialysis. J Pulm Respir Med 9: 484. doi: 10.4172/2161-105X.1000484

Page 3 of 6

\begin{tabular}{|c|c|c|}
\hline Variable & Reference Range, Adults ${ }^{\circ}$ & On initial Evaluation \\
\hline Hemoglobin (g/dl) & $12.0-15.0$ & 9.8 \\
\hline Hematocrit (\%) & $36.0-44.0$ & 30 \\
\hline White-cell count (per $\mathrm{mm}^{3}$ ) & $4,500-10,000$ & 7,940 \\
\hline \multicolumn{3}{|c|}{ Differential (\%) } \\
\hline Neutrophils & $35.0-66.0$ & 70.3 \\
\hline Lymphocytes & $24.0-44.0$ & 17.9 \\
\hline Monocytes & $2.0-10.0$ & 7.6 \\
\hline Eosinophils & $0.0-0.5$ & 2.8 \\
\hline Basophils & $0.0-2.0$ & 0.4 \\
\hline Platelet count (per mm ${ }^{3}$ ) & $15,000-450,000$ & 298,000 \\
\hline Sodium (mmolniters) & $135-145$ & 137.89 \\
\hline Potassium (mmolniters) & $3.4-4.8$ & 4.52 \\
\hline Chloride (mmol/liters) & $100-108$ & 95.83 \\
\hline Magnesium (mg/di) & $1.6-2.41$ & 1.9 \\
\hline Calcium (mg/di) & $8.5-10.5$ & 8.71 \\
\hline Urea nitrogen (mg/di) & $8-23$ & 43.33 \\
\hline Creatinine(mg/di) & $0.6-1.2$ & 4.73 \\
\hline Glucose (mg/di) & $70-110$ & 108.91 \\
\hline Tola prolein $(\mathrm{g} / \mathrm{dl})$ & $6.4-8.7$ & 5.21 \\
\hline Lactate Dehydrogenase (Uiliters) & $85-227$ & 259.9 \\
\hline Reactive C Protein (mg/liters) & $0.00-5.0$ & 11.87 \\
\hline Procalcitonin $(\mathrm{ng} / \mathrm{ml})$ & $0.0-0.009$ & 0.27 \\
\hline
\end{tabular}

${ }^{*}$ Ranges used at Hospital Vivian Pellas for adults who are not pregnant and not have medical conditions that could affect the results.

Table 1: Laboratory data.

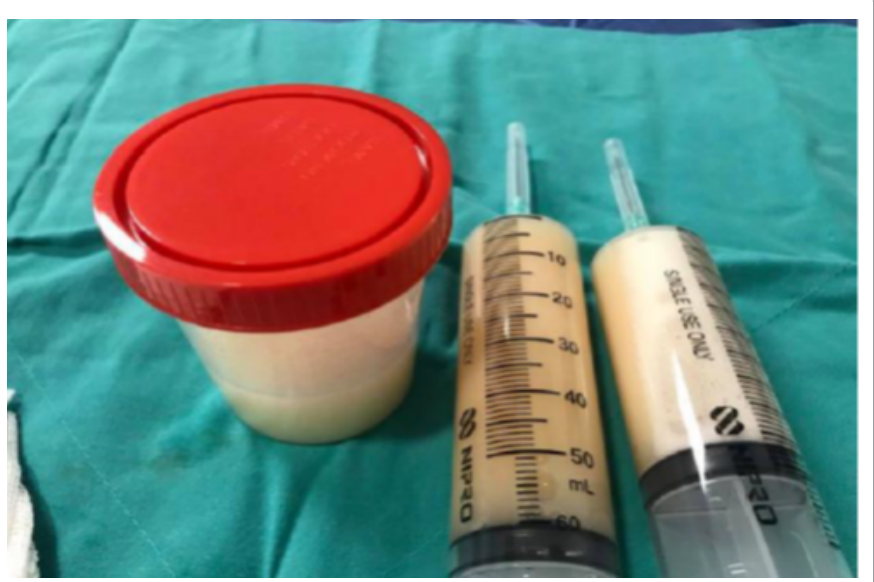

Figure 3: Thoracocentesis drained a yellow milky, cloudy, odourless pleural fluid.

and a repeated thoracic CT scan shown resolution of parenchymal opacities and mediastinal lymphadenopathy. The patient continued on hemodialysis, completed six months of oral voriconazole without recurrence of chylothorax after one year of follow up.

\section{Discussion and Revision of Literature}

Our patient is a young man with end-stage renal disease in hemodialysis of non-traditional cause; which is the leading cause of death among working-age men in lower-altitude agricultural communities in northwest Nicaragua and has an estimated prevalence of $20 \%$ being considered an epidemic of multifactorial cause (sugar cane workers, heat stroke, urinary infections) since 2009; [5-7] contributing to the global epidemic of CKD. As result our team attends 928 patients each month for hemodialysis and this is the first case of chylothorax that we found.

\begin{tabular}{|c|c|}
\hline \multicolumn{2}{|c|}{ Physical and Chemical analysis } \\
\hline $\mathrm{pH}$ & 8 \\
\hline Glucose (mg/dl) & 102.64 \\
\hline Protein $(\mathrm{g})$ & 2.64 \\
\hline Lactate Dehydrogenase (Units) & 136.03 \\
\hline Triglycerides $(\mathrm{mg} / \mathrm{dl})$ & 380 \\
\hline Cholesterol (mg/dl) & 43.19 \\
\hline \multicolumn{2}{|c|}{ Cell Count and Differential } \\
\hline Leucocytes (per $\mathrm{mm}^{3}$ ) & 1,434 \\
\hline PMN (\%) & 1 \\
\hline Lymphocytes & 99 \\
\hline \multicolumn{2}{|l|}{ Light Criteria } \\
\hline Pleural Fluid Protein/Serum Protein Ratio & 0.5 \\
\hline Pleural Fluid LDH/Serum LDH Ratio & 0.52 \\
\hline Pleural Fluid LDH & $<2 / 3$ serum $\mathrm{LDH}$ \\
\hline \multicolumn{2}{|c|}{ Microbiology and Pathologic analysis } \\
\hline Gram Stain and cultures & No detected organism \\
\hline Acid-Fast Bacilli Smear & Negative \\
\hline GeneXpert-Mtb-Rif & No detected \\
\hline Cytology & Negative \\
\hline PMN: Polymorphonuclear leucocytes, LD & ctate Dehydrogenase \\
\hline
\end{tabular}

Chylothorax is an infrequent complication of CKD patients in hemodialysis and can become a debilitating problem with metabolic and immunologic wasting if not addressed promptly.

Our literature review found only 11 cases reported (Table 3) [8-20], mainly related to vascular access and CVC placement complications (thrombosis, stenosis, obstruction of neck and central veins, direct injuries of TD); which were important differential diagnosis in our case. 


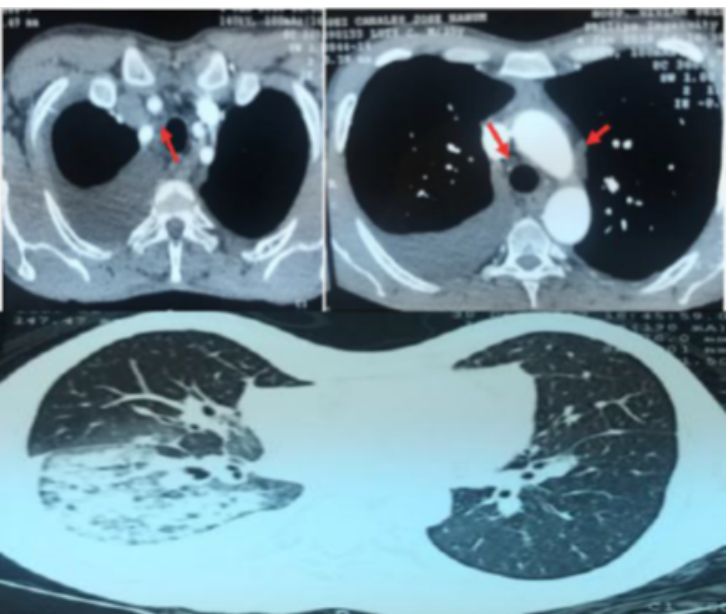

Figure 4: CT scan of thorax showing mediastinal lymph nodes enlargements (red arrows) and coalescent nodular opacities.

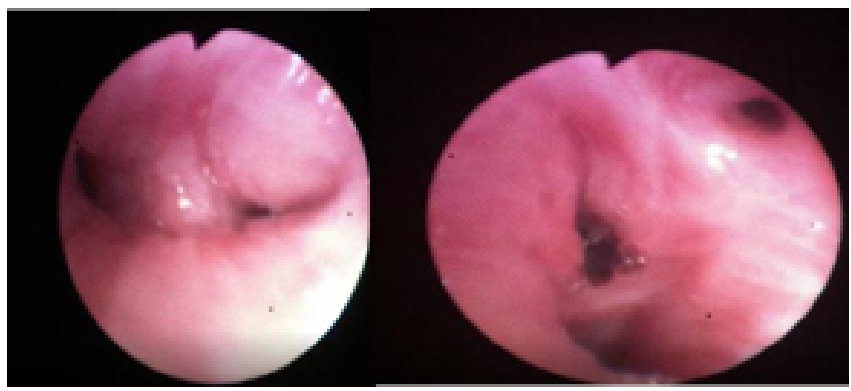

Figure 5: Bronchoscopy showing extrinsic bronchial compression on left uppe lobe.

Others uncommon causes of chylothorax reported in this population include infection as tuberculosis [11] and histoplasmosis [12] that cause chylothorax via external pressure/obstruction of TD by mediastinal lymphadenopathy or direct erosion, where the immunocompromised state of patients on hemodialysis predisposes them to this type of infections. However, we found no reports of pulmonary aspergillosis as a cause of chylothorax.

To determinate the cause of chylothorax in our patient is difficult, but probably pulmonary aspergillosis played a pathogenic role via a mechanism similar to tuberculosis and histoplasmosis. In favor of this theory is the absence of other identifiable etiology, a plausible mechanism of obstruction of TD by mediastinal lymphadenopathy and no recurrence after antifungal therapy.

In this case, the resolution of chylothorax was achieved with the performance of LAG, which served for diagnostic and therapeutic purposes and allowed us to offer our patient a definitive treatment with pleurodesis.

Traditional management for cases of chylothorax (mainly traumatic) refractory to conservative treatment has been the thoracic duct ligation through a right open thoracotomy or closure of the site of duct laceration through an open thoracotomy with a $96 \%$ success rate or through videoassisted thoracoscopic surgery (VATS). Surgical pleurodesis is reserved for patients with high operative risk which has an $83 \%$ success rate [2123]. However alternative less invasive techniques has gain acceptance

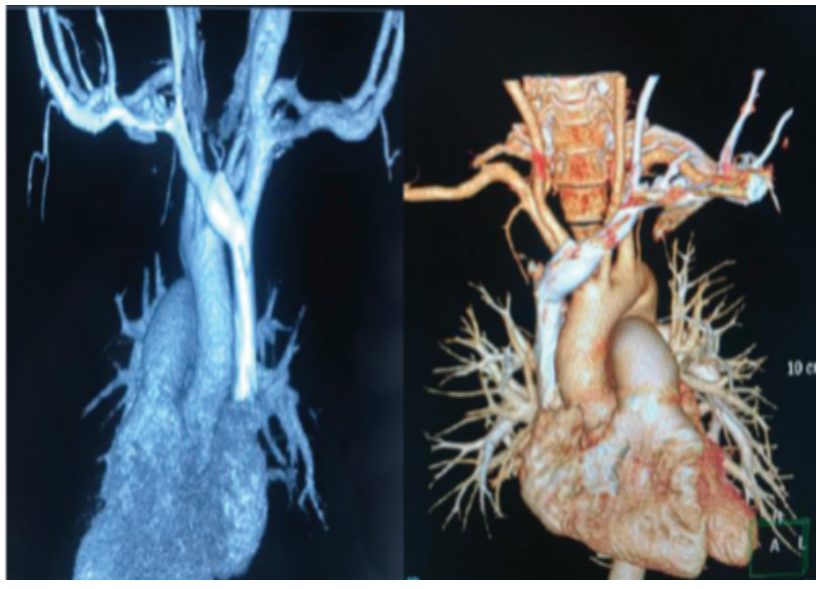

Figure 6: Reconstruction of a Flebo-TC that ruled-out obstruction/thrombosis of neck and central veins as cause of obstruction/compression of thoracic duct.
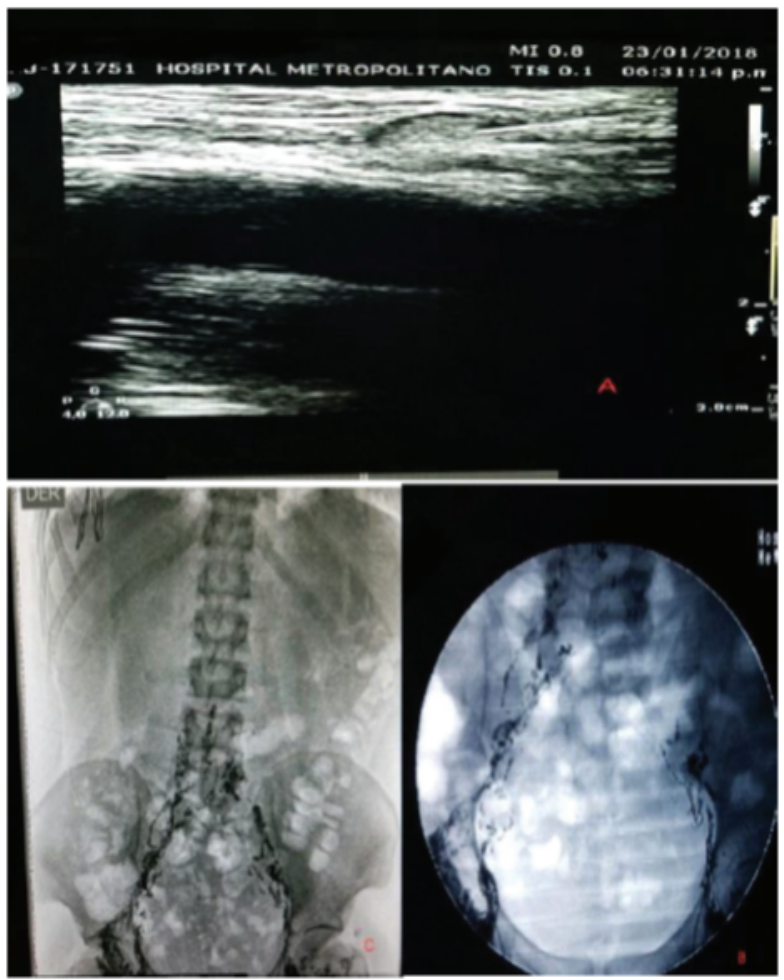

Figure 7: Intranodal Lymphangiography (LAG). (A) Inguinal lymph node access; (B) injection of Lipiodol; (C) Lymphangiography not showing leakage of thoracic duct.

and popularity in last decade including percutaneous embolization of TD (TDE) [24] and lymphatic interventions which includes LAG and TDE with a pooled technical success rate for both of $94.2 \%$ and pooled clinical success rate for LAG and TDE of $56.6 \%$ and $79.4 \%$ respectively according to a recent systematic review and meta-analysis [25].

None of the techniques described above were performed in endstage renal patients in hemodialysis but as illustrated in our case, it is worthwhile to try less invasive procedures to treat chylothoraces refractory to conservative treatment in patients without identifiable 
Citation: Miranda JI, Gutiérrez LOG, Blanco AAS, Durán CJQ, López SEM, et al. (2019) Chylothorax in a Patient with Pulmonary Aspergillosis and Chronic Renal Disease in Hemodialysis. J Pulm Respir Med 9: 484. doi: 10.4172/2161-105X.1000484

Page 5 of 6

\begin{tabular}{|c|c|c|c|}
\hline Authors & Etiology & Main Mechanism & Reference \\
\hline De Freitas-Gonzalez, et al. & Thrombosis of right jugular CVC & Stenosis/Obstruction of superior vena cava & [10] \\
\hline Hugh IP, et al. & $\begin{array}{l}\text { Tuberculosis with posterior } \\
\text { Mediastinal lymphadenopathy }\end{array}$ & Obstruction/Erosion of thoracic duct & [11] \\
\hline Shah S, et al. & $\begin{array}{c}\text { First case of Histoplasmosls in adults } \\
\text { as a cause of chylothorax }\end{array}$ & $\begin{array}{l}\text { External compression/Erosion of } \\
\text { thoracic duct. }\end{array}$ & [12] \\
\hline Benhamou R, et al. & Licamidipine & $\begin{array}{c}\text { Licardnidipine has been associated with } \\
\text { chylothorax in Hispanic and Japanese } \\
\text { populations during dialysis. }\end{array}$ & [13] \\
\hline Torres-Guineas M, et al. & $\begin{array}{l}\text { Thrombosis of right jugular } \\
\text { CVC/Direct injury to thoracic duct } \\
\text { during replacement of left jugular } \\
\text { CVC }\end{array}$ & $\begin{array}{l}\text { Superior Vena Cava stenosis/Direct } \\
\text { injury to thoracic duct. }\end{array}$ & [14] \\
\hline Limesh M, et al. & $\begin{array}{l}\text { Left innominate vein stenosis related } \\
\text { to eve placement }\end{array}$ & Obstruction/Compression of thoracic duct & [15] \\
\hline Adeklle A, et al. & $\begin{array}{c}\text { Catheter Induced superior vena cava } \\
\text { stenosis }\end{array}$ & Obstruction/Compression of thoracic duct & [16] \\
\hline Riza AM, et al. & Constrictive pericarditis & $\begin{array}{l}\text { Transdiaphragmatic movement of } \\
\text { Chylous ascites of Cardiac caused - elevated } \\
\text { right-sided venous pressure }\end{array}$ & [17] \\
\hline Un SH, et al. & Nephrotic syndrome & $\begin{array}{l}\text { Transdiaphragmatic movement of } \\
\text { chylous ascites }\end{array}$ & [18] \\
\hline Geilh O, et al. & $\begin{array}{c}\text { Catheter induced thrombosis of major } \\
\text { Neck veins, superior vena cava and } \\
\text { azygos vein }\end{array}$ & Obstruction/Compression of thoracic duct & [19] \\
\hline Bonin VM, et al. & Nephrotic syndrome & $\begin{array}{l}\text { Transdiaphragmatic movement of } \\
\text { chylous ascites }\end{array}$ & [20] \\
\hline
\end{tabular}

Table 3: Summary of chylothorax cases reported in patients with end-stage renal disease in hemodialysis.

leakage of TD, including LAG with therapeutic purposes.

\section{Conclusion}

Pulmonary aspergillosis is not recognized as a cause of chylothorax, but in our patient with immunocompromised sate of CKD probably played an etiopathogenic role via mediastinal lymphadenopathy and should be considered in the differential diagnosis. In the treatments of chylothorax in end-stage renal disease patients in hemodialysis, lymphatic interventions could have a respectable efficacy and are less invasive options. We suggest consider LAG and TDE as first line therapy for this population.

\section{References}

1. Huggins JT (2010) Chylothorax and cholesterol pleural effusions. Semin Respir Crit Care Med 31: 743-750.

2. Doerr CH, Miller DL, Ryu JH (2001) Chylothorax. Semin Respir Crit Care Med 31: 617-626.

3. Kwon SS, Falk A, Mitti HA (2002) Thoracic duct injury associated with left internal jugular vein catheterizations. J Vasc Interv Radiol 13: 337-339.

4. Platis IE, Nwogu CE (2006) Chylothorax. Thorac Surg Clin 16: 209-214.
5. Skouras V, Kalomenidis I (2010) Chylothorax: Diagnostic approach. Curr Opin Pulm Med 16: 387-393.

6. Weiner DE, McClean MD, Kaufman JS, Brooks DR (2013) The Central American Epidemic of CKD. Clin J Am Soc Nephrol 8: 504-511.

7. Kupferman J, Ramírez-Rubio O, Amador JJ, López-Pilarte D, Wilker EH, et al. (2018) Acute kidney injury in sugarcane workers at risk for Mesoamerican nephropathy. Am J Kidney Dis 72: 475-482.

8. Doerr CH, Allen MS, Nichols FC, Ryu JH (2005) Etiology of chylothorax in 203 patients. Mayo Clin Proc 80: 867-870.

9. Cortés-Télles A, Rojas-Serrano J, Torre-Bouscoulet L (2010) Quilotórax: Frecuencia, causas y desenlaces. Neumol Cir Torax 69: 157-162.

10. De Freitas-Gonzalez EM, Villegas-Alcázar JA, García-García S (2017) Chylothorax in a patient receiving hemodialysis. Arch Bronconeumol 53: 404.

11. Hugh IP, Schomberg LE, Ahmed L (2013) Pleural effusions in a patient with tuberculosis on dialysis. Lancet 382: 570 .

12. Shah S, Prasoon V (2017) Unusual case of histoplasmosis presenting as chylothorax in a renal transplant patient. Am J Kidney Dis 69: A1-A105.

13. Benhamou R, Simon I, Nortier J, Baudox T, Catalano C (2018) Chylothorax in hemodialysis: Think of lercanidipine. Nephrology \& Therapeutics 14: 306-307.

14. Torres-Guinea M, De-Arriba G, Basterrechea MA, Ocana J (2008) Chylothorax: 
Citation: Miranda JI, Gutiérrez LOG, Blanco AAS, Durán CJQ, López SEM, et al. (2019) Chylothorax in a Patient with Pulmonary Aspergillosis and Chronic Renal Disease in Hemodialysis. J Pulm Respir Med 9: 484. doi: 10.4172/2161-105X.1000484

An uncommon cause of pleural effusion in patients on hemodialysis. Nefrologia 28: 353-354.

15. Limesh M, Desai A, Kedalaya PG, Renuka S (2017) A case of chylothorax in a hemodialysis patient with left innominate vein stenosis. Indian J Nephrol 27: 234-236.

16. Adekile A, Adegoroye A, Tedla F, Levin D, Slifu MO (2009) Chylothorax and chylopericardial tamponade in a hemodialysis patient with catheter induced superior vena cava stenosis. Semin Dial 22: 576-579.

17. Riza-Altiparmak M, Avsar D, Yanik S (2004) Chylous ascites and chylothorax due to constrictive pericarditis in a patient undergoing haemodialysis. Neth $\mathrm{J}$ Med 62: 59-61.

18. Lin SH, Lin YF, Shih YL (2001) An unusual complication of nephrotic syndrome: Chylothorax treated with hemodialysis. Nephron 87: 188-189.

19. Gheith O, Gheith O, Al-Otaibi T, Nampoory MR, Attia H, et al. (2014) Bilateral chylothorax in a renal transplant recipient: Case report and literature review. Exp Clin Transplant 12: 148-151.
20. Bonin-Vilaplana M, Pelegri-Santos A, Parra-Ordaz O (2006) Quilotórax y ascitis quilosa: Manifestación inicial de un síndrome nefrótico. Med Clin (Barc) 127 716-719.

21. Watanabe A, Koyanagi T, Shinji N, Higami T (2007) Supradiaphragmatic thoracic duct clipping for chylothorax through left-sided video-assisted thoracoscopic surgery. Eur J Cardiothorac Surg 31: 313-314.

22. Paul S, Altorki MK, Port JL, Stiles BM, Lee PC (2009) Surgical management of chylothorax. Thorac Cardiov Surg 57: 226-228.

23. Bender B, Vijayashree M, Chamberlain RS (2015) The changing management of chylothorax in the modern era. Eur J Cardiothorac Surg pp: 1-7.

24. Cope C (2004) Management of chylothorax via percutaneous embolization. Curr Opin Pulm Med 10: 311-314

25. Kim PH, Tsauo J, Shin JH (2018) Lymphatic interventions for chylothorax: A systematic review and meta-analysis. J Vasc Interv Radiol 29: 194-202. 